\title{
A “fala do desenvolvimento" em Belterra e a transformação do lugar em dois contextos de modernização
}

\section{The "speech development" in Belterra, and the alterations of the environment in two contexts of modernization}

José Carlos Matos Pereira - Sociólogo e Doutorando do Programa de Pós-Graduação em Ciências Sociais (PPCIS), da Universidade do Estado do Rio de Janeiro.

Márcia da Silva Pereira Leite - Doutora em sociologia pelo Programa de Pós-Graduação em Sociologia e Antropologia da UFRJ. Pós-doutorado na EHESS - École des Hautes Études en Sciences Sociales - e no Iuperj - Instituto Universitário de Pesquisas do Rio de Janeiro da UCAM. Pesquisadora do CNPq. Professora adjunta do Departamento de Ciências Sociais da Universidade do Estado do Rio de Janeiro.

\section{Resumo}

Sessenta e seis anos separam o fim da experiência do plantation de seringa de Henry Ford (1945) da presença da soja na cidade paraense de Belterra, na Amazônia brasileira. No primeiro caso, temos a construção de uma cidade na floresta e a criação de uma hierarquia sociofuncional com base no sistema fordista de produção. No segundo, uma ação planejada e seletiva que teve apoio político em diversos níveis, financiamento público, flexibilização da legislação ambiental e estudos científicos que subsidiaram a melhor localização do empreendimento. A ligação entre os dois períodos encontra-se na produção do desarranjo dos modos de vida preexistentes, no uso predatório da natureza e na enunciação de estereótipos pelos "de fora" contra a população do lugar sob o abrigo da "fala do desenvolvimento".

\section{Palavras-chave}

Amazônia. Fordismo. Modos de vida. Fala do desenvolvimento". Cidade. Verticalidade.

\begin{abstract}
Sixty-six years separate the end of Henry Ford's syringe Plantation experience (1945) from the presence of soy in the town of Belterra in the Brazilian Amazon. In the first case we have the construction of a city in the forest and the creation of a socialfunctional hierarchy based on the Fordist system of production. The latter case involves a planned and selective action that counts on political support at various levels, public funding, easing of environmental law and scientific studies that subsidised the choice of the best location of the project. The connection between the two periods is the breakdown of preexisting ways of life, the predatory use of nature and the announcement of stereotypes by "outsiders" against the local peoples as the "development speech".
\end{abstract}

\section{Keywords}

Amazon. Fordism. Lifestyles. "Development speech". Cty. Verticality. 


\section{INTRODUÇÃO}

Sessenta e seis anos separam o fim da experiência do plantation de seringa de Henry Ford, em 1945, da presença recente da soja na cidade de Belterra (PA), na Amazônia brasileira. No primeiro caso, temos a construção de uma cidade-empresa na floresta, a criação de uma hierarquia sociofuncional com base no sistema fordista de produção e uma sociabilidade marcada pela evitação da convivência dos americanos em relação aos brasileiros, materializada através da criação de espaços exclusivos de uso dos primeiros. Nesse período, Belterra aparece para o cenário urbano, não pelo espraiamento da periferia, como no processo urbanoindustrial vivido por várias cidades brasileiras, mas através da urbanização, pela verticalidade (SANTOS, 2006). Trata-se, segundo este autor, da articulação de espaços descontínuos propiciada pela ação seletiva do capital com base no apoio estatal, cujas escalas vão desde o lugar onde se realizou o projeto, passando pela mediação governamental nas esferas estadual e federal, chegando até os Estados Unidos, onde se localizavam as fábricas de Henry Ford.

No segundo caso analisado, a presença da soja na cidade e no seu entorno nos anos 2000 e o novo contexto de produção do urbano resultam de uma ação planejada e seletiva que tem apoio político em diversos níveis, financiamento público, flexibilização da legislação ambiental e estudos científicos que subsidiaram a melhor localização do empreendimento. A ligação entre os dois períodos encontra-se no desarranjo dos modos de vida preexistentes ${ }^{1}$, no uso predatório da natureza e na enunciação de estereótipos pelos de "de fora", contra a população do lugar sob o abrigo da "fala do desenvolvimento", que examinaremos no item seguinte.

Argumentamos ser possível, por meio da análise dos modos de vida existentes na cidade de Belterra, fazer a mediação entre esses dois períodos de tempo, examinando como se deu a inserção do lugar, sob a lógica do capital na economia mundializada, que impõe novas formas de uso e apropriação da natureza em bases intensivas, industriais e predatórias. Embora os contextos econômicos e técnicos dos dois períodos não sejam equivalentes, apenas relacionais, os impactos socioambientais negativos guardam proximidade, já que a premissa através da qual aquela inserção se verificou, em ambos os casos, ancorou-se na lógica de mercantilização da vida e da natureza do lugar.

1 Os modos de vida, segundo Cândido (1942), estão relacionados aos hábitos, condutas, técnicas e instituições adquiridos por herança cultural ou desenvolvidos localmente. Dessa forma, envolvem as formas de produção da existência e a satisfação de necessidades imediatas (relações com a natureza, técnicas usadas para adquirir e produzir alimentos, construir moradia e vestuário, as preferências alimentares) e as relações de sociabilidade. 


\section{O PROCESSO CIVILIZATÓRIO CAPITALISTA PARA A AMAZÔNIA}

A "fala do desenvolvimento", como denominamos a produção de sentidos sobre a Amazônia brasileira nos contextos estudados, envolve elementos que merecem nossa atenção, já que orientam o olhar de diversos atores sociais, definem seu papel econômico e político e essencializam os modos de vida dos grupos sociais que nela vivem. Seus enunciados básicos podem ser formulados da seguinte forma: uma região selvagem a ser dominada; uma riqueza natural adormecida e diversa que precisa ser economicamente valorizada; um lugar despovoado que precisa ser ocupado; um povo destituído da capacidade de usar e transformar em riqueza o patrimônio que detém.

Termos como "selva" e "selvagem" expressam as características do lugar e os povos que nele vivem. A sociedade indígena, por exemplo, para esse caso, não se refere a etnia. É sinônimo de atraso, embora essa nominação também se estenda para agricultores, extrativistas e quilombolas. Parte-se, segundo essa premissa, da ideia de vazio sociocultural que precisa ser preenchido pelo processo civilizatório.

Segundo Grandin (2010, p. 18), o jornal Washington Post e a Revista Time noticiaram, à época, que o projeto de industrializar a selva proposto por Henry Ford era uma possibilidade do homem branco levar a magia da civilização "para o mundo selvagem".

Enunciados como este não foram produtos exclusivos da imprensa norteamericana. Publicações com o mesmo teor foram realizadas por jornais do Rio de Janeiro e da própria Amazônia, como é o caso do jornal Folha do Norte. Referimo-nos, especialmente, às matérias dedicadas à presença do capital americano às margens do rio Tapajós, no oeste do Pará, e ao que se relacionou às reportagens veiculadas quando da visita do então presidente Getúlio Vargas à Amazônia, na década de 1940.

Fizeram-se os primeiros viveiros imensos [de seringueiras] onde foram lançadas as primeiras sementes prodigiosas e de onde derrubavam um trecho de mata virgem abrindo clareiras para a civilização e para o futuro, eram aproveitadas

Essa expressão inspira-se nas formulações de Teresa Caldeira, quando propõe a "fala do crime" para analisar as representações dos moradores de camadas médias e altas na cidade de São Paulo sobre quem eram as pessoas que praticavam crimes na cidade. A autora reconstitui o discurso padrão de seus entrevistados que acusavam os migrantes nordestinos e nortistas, os pobres e negros moradores de favelas. Em muitos dos casos, não tinham visto quem praticava os delitos, mas pressupunham serem estes os grupos responsáveis pela criação da situação de insegurança, medo e violência. "A fala do crime constrói sua reordenação simbólica do mundo elaborando preconceitos e naturalizando a percepção de certos grupos como perigosos [...] ela [...] criminaliza certas categorias sociais. Essa criminalização simbólica é um processo social dominante e tão difundido que até as próprias vítimas do estereótipo (os pobres, por exemplo) acabam por produzi-lo, ainda que ambiguamente" (CALDEIRA, 2000, p. 10). 
as suas essências e preparadas racionalmente o terreno, com exemplares da planta rica e maravilhosa, que há de marcar ainda, com sua belleza hieratica da sua elegancia typica, e com selva potencial do seu valor mercantil, o symbolo da redempção economica da gleba [...] multiplicavam-se os viveiros onde as sementes eram lançadas sob as bençãos do trabalho e os auspicios do sol tropical, e pare passo, avultavam-se os serviços de desbravamento da selva bruta e elevavam-se truinphalmente as construções das modernas urbes [...] dando execução aos seus planos de estabelecimento duma grandiosa indústria na Amazônia, a Companhia Ford Industrial do Brasil continua a desenvolver as suas proficuas actividades no Tapajós, onde estão situadas as terras da concessão adquiridas [junto] ao governo do estado [...] uma architectura gigantesca, a estructura definitiva da 'fordlandia brasileira', futuro centro de producção e irradiação da mais útil e procurada das materias primas de que as fabricas do mundo vivem sempre famintas [...] (FOLHA DO NORTE, 01/01/1934, p. 1, grifos nossos) ${ }^{3}$.

O presidente Getúlio Vargas, no proposito de conhecer intimamente as necessidades da Amazônia e promover a sua entrada definitiva em novos caminhos largos de progresso e grandeza, chegará hoje à tarde a Belém, no avião "Douglas" da Panair [...] (FOLHA DO NORTE, 05/10/1940, p. 1, grifos nossos).

Convém observar que, desde a década de 1930 e durante a vigência do Estado Novo no Brasil, estava em curso o projeto de modernização capitalista sob o protagonismo estatal de Vargas. Como sustenta Werneck Vianna (1978, p. 141), "a revolução pelo alto [consistiu] numa forma de induzir a modernização econômica a partir da intervenção política": o Estado se fez presente como ator principal, dando sustentação política e econômica ao capital encarregado de assegurar a industrialização do país. Esse período marcou o avanço da acumulação capitalista no Brasil; a redefinição do papel econômico do Estado; a implantação de um núcleo industrial de base; e a afirmação do modelo urbano-industrial enquanto eixo predominante da economia brasileira (MENDONÇA, 1990).

Desde então. a "fala do desenvolvimento" prolongou-se e naturalizou-se como discurso, encontrando sua justificativa na prática modernizadora capitalista proposta pelo Estado para o país. Em relação ao caso que nos interessa, vale lembrar que, em 1970, o general Médici e sua comitiva estiveram na Amazônia para a obra inaugural da Rodovia Transamazônica, cuja missão era ligar a região ao Nordeste brasileiro. O evento foi noticiado como a "arrancada para conquistar o gigante mundo verde".

Descendo do carro que o conduzia, o presidente hasteou o pavilhão brasileiro em um mastro improvisado no tronco de uma árvore, enquanto uma banda militar tocava o Hino Nacional. Depois, descerrou uma placa de bronze incrustrada no tronco de uma grande castanheira com cerca de dois metros de diâmetro, na qual estava inscrito: "Nestas margens do Xingu, em plena selva amazônica, o

Mantivemos a ortografia da época. 
Sr. Presidente da Republica dá inicio à construção da Transamazônica, numa arrancada histórica para a conquista deste gigantesco mundo verde" (FOLHA DE SÃO PAULO, 10/10/1970).

Esses exemplos mostram como os enunciados sobre a Amazônia, muitas vezes, ganham uma dimensão de invenção que a associam ao atraso, ao vazio humano, sugerindo um descompasso desta com a sociedade nacional e remetendo ao estereótipo da indolência, da inaptidão e da má utilização de seus recursos por sua população, conforme propôs Mendes (1974).

Queremos com essa argumentação sustentar que a "fala do desenvolvimento" naturaliza o olhar sobre a Amazônia e serve de referência conceitual quando se pensa nesta região, ao mesmo tempo em que o projeto modernizador capitalista é apresentado como aquele que cria as condições para colocá-la no caminho do "crescimento", do "progresso" e do "desenvolvimento", através da mercantilização de sua riqueza, vista como estoque estratégico de recursos naturais. Temos então, aqui, os dois eixos estruturantes da análise para pensá-la na divisão internacional do trabalho e a partir do papel que cumpre no processo de acumulação do capital.

Em "O processo civilizador", Norbert Elias (1994), discutindo o uso corrente dos conceitos de kultur e civilização nas sociedades alemã e francesa, observa que os mesmos

"lançaram raízes. Estabeleceram-se. [...] O indivíduo encontra essa cristalização já em suas possibilidades de uso. [...] Usa [essas palavras] porque lhe parece uma coisa natural, porque desde a infância aprende a ver o mundo através da lente desses conceitos" (ELIAS, 1994, p. 26).

Este autor nos serve de base para analisar como determinados conceitos e representações informam e presidem a ação dos grupos sociais, das instituições ou de uma sociedade inteira, como nos dois períodos históricos vividos por Belterra.

\section{O CAPITAL AMERICANO NA AMAZÔNIA}

Data de 1928 a chegada da Companhia Industrial Ford do Brasil (CFIB) à localidade de Boa Vista, às margens do rio Cupari, posteriormente denominada de Fordlândia. Hospitais, oficinas, casas, escolas, cinemas, estradas, serraria, depósitos, restaurante, campo de futebol, igreja, sistema de abastecimento de água e energia, ferrovia, dentre outros, constituíram a infraestrutura erguida pelo empreendimento americano. O elemento motivador desta ação deveu-se à racionalidade capitalista demandante de matéria-prima para a indústria automobilística norte-americana; às disputas entre as potências europeias pelo controle do mercado internacional 
da borracha; e às expectativas de um novo ciclo de desenvolvimento econômico pós-boom da borracha ansiado pelo governo federal brasileiro e pelas oligarquias da Amazônia (COSTA, 1993).

A CFIB promoveu o recrutamento de mão de obra dentro e fora da região. No ano de 1929, a força de trabalho era formada de 2.825 empregados, inclusive estrangeiros. Eram migrantes, principalmente nordestinos e pessoas oriundas da Amazônia, como aquelas residentes nas proximidades dos rios Tapajós, Arapiuns, Amazonas e Lago Grande (AMORIM, 1995; SENA, 2008). O grupo minoritário dos estrangeiros era constituído por holandeses, italianos, russos, japoneses, chilenos, chineses, peruanos, portugueses, barbadianos, alemães e sul-africanos, e compunham o quadro sociofuncional, em Fordlândia e Belterra, formado por técnicos especializados e peões, cuja direção estava sob coordenação americana, conforme relatos colhidos em campo ${ }^{4}$.

Apesar dos altos investimentos, no valor de 20 milhões de dólares, o projeto fracassou em Fordlândia, em 1934, e depois em Belterra, no ano de 1945. No primeiro caso, entre os fatores que contribuíram para esta situação, podemos citar o atraso nas operações, a má escolha da localização do empreendimento e o "mal das folhas", doença que atacou os seringais (SENA, 2008), além da forma acidentada do terreno para o desenvolvimento do cultivo da seringueira, do distanciamento do projeto em relação ao porto de Santarém (principal cidade naquela região e lugar de concentração da mão de obra disponível) e da dificuldade de navegação dos navios maiores durante o período da estiagem (CRULS, 1939).

Ademais, os homens enviados por Henry Ford para a Amazônia com a missão de implantar o projeto mostravam desconhecimento sobre clima, solo, rios, cultivo de seringueiras e sobre a vida social na região. Eles tinham uma visão simplista da técnica e desprezo pelo conhecimento científico. Eram práticos que faziam antes e planejavam depois, e queriam repetir na floresta os mesmos procedimentos usados na linha de produção de uma fábrica. A Companhia concluiu, então, que as plantações em Fordlândia não davam retorno econômico. E, mesmo tendo investido US\$ 7 milhões de dólares e seis anos de trabalho em Fordlândia, depois de consultar especialistas sobre o assunto, optou, em 1934, pelo deslocamento para Belterra, onde desenvolveria a nova plantação e construiria uma nova cidade (GRANDIN, 2010) ${ }^{5}$.

$4 \quad$ Todo o material empírico que sustenta a elaboração do argumento deste artigo foi colhido por José Carlos Matos Pereira, no âmbito de sua pesquisa de doutoramento no Programa de PósGraduação em Ciências Sociais da Universidade do Estado do Rio de Janeiro, desenvolvida sob orientação de Márcia Pereira Leite e atualmente em conclusão.

5 Data de 04/05/1934 a assinatura do termo de permuta através do qual o governo brasileiro concedeu novas terras para serem exploradas pela Companhia Ford Industrial do Brasil, denominadas de Belterra (COSTA, 1993). 


\section{EXPERIÊNCIA DA FORD EM BELTERRA: DO MODO DE VIDA DO LUGAR À PRODUÇÃO DO URBANO}

O deslocamento do projeto para Belterra constituiu uma tentativa da Companhia de superar o fracasso experimentado em Fordlândia. Com este objetivo, a CFIB realizou a plantação em áreas mais planas, importou um novo tipo de seringueira e usou enxerto nas mudas para torná-las mais resistentes às pragas. Construiu um porto em águas mais profundas e se localizou mais próxima da cidade de Santarém para facilitar o recrutamento da mão de obra. Por fim, permitiu que terceiros pudessem explorar na cidade a oferta de serviços, como bar, sapataria, padaria e barbearia, por exemplo, mas também montou a comissária (pequeno comércio) para ofertar produtos alimentícios mais baratos para seus funcionários. Além disso, permitiu que eles pudessem desenvolver, em seus lotes de moradia, atividades ligadas à agricultura e à criação de animais de pequeno porte, uma concessão para evitar situações como o "Quebra-Panela”, movimento que consistiu numa revolta dos trabalhadores contra a imposição de novos hábitos alimentares por parte dos americanos ${ }^{6}$.

Interessa-nos analisar, nesta seção, como se deu a produção do urbano em Belterra. Para isto, devemos nos perguntar que transformações ocorreram naquele lugar aonde a cidade não existia e as pessoas viviam basicamente da atividade agrícola, da pesca e da coleta dos frutos da floresta? Que ações o capital realizou para concentrar mão de obra? E em que bases ocorreu a (re)socialização da população migrante na cidade-empresa de Henry Ford??

Recorremos a Lefebvre, que apresenta um esquema abstrato para analisar a urbanização, cuja proposição parte da "urbanização zero (inexistência da cidade, a predominância completa da vida agrária, da produção agrícola, do campo) [até chegar à] urbanização cem por cento (absorção do campo pela cidade, predominância completa da produção industrial até mesmo na agricultura)" (LEFEBVRE, 1991, p. 71). Se fizermos um exercício empírico tomando por base parte dessa proposição teórica, podemos apresentar o seguinte quadro em relação à Belterra: com a CFIB, o grande capital levou para a cidade e para o urbano

O "Quebra-Panela" foi o movimento dos trabalhadores em Fordlândia por melhoria nas condições de trabalho e salários e, sobretudo, na alimentação que lhes era servida e não seguia os padrões da região. "Teve americano que fugiu de canoa para o outro lado do rio com medo de ser morto". Este é o relato de um ex-seringueiro, lembrando, em entrevista, o que lhe contaram seus pais e outras pessoas com que conviveu e que presenciaram esses fatos. Seu pai era cearense e trabalhou como operador de máquinas em Fordlândia (Erasmo, Outubro, 2009). A cidade-empresa consistiu numa estratégia do capital para dotar de infraestrutura e serviços urbanos lugares que não ofertavam condições para o desenvolvimento da atividade industrial (PIQUET, 1998). 
grupos sociais que até então viviam da extração de frutos da floresta, da pesca e da agricultura às margens dos rios Tapajós, Arapiuns, Amazonas e Lago Grande, deslocando-os do lugar do trabalho (o campo, os rios, a floresta) e das relações socioculturais que os envolviam (o rural e a natureza). A caça, a pesca, o cultivo da terra, a brincadeira com as crianças na praia, a lavagem de roupa, o passeio de canoa e o banho de rio deixaram de ser parte de seu cotidiano, quando o barco da CFIB passou nas localidades recrutando mão de obra para levá-la até o acampamento provisório da empresa, na localidade de Porto Novo, em Belterra, onde se iniciou o projeto. Estes são elementos comuns das várias narrativas colhidas por meio de entrevistas, que nos permitiram situar o contexto de implantação da Companhia Ford Industrial do Brasil no lugar.

Apesar da escassez da mão de obra para as plantações, a orientação interna na CFIB era a de manter distância dos indígenas, uma vez que eles não eram considerados "domesticados", nem "aptos ao trabalho". Adjetivos como "preguiçosos", "indisciplinados" e "traiçoeiros" faziam parte do enunciado de seus dirigentes, conforme apresenta o estudo de Grandin (2010).

Naquele lugar, como indicam os relatos sobre o modo de vida preexistente, a atividade humana não era predatória e o dinheiro pouco circulava. A aparição deste, através do salário, constituiu um forte atrativo que, associado à possibilidade de melhoria nas condições de vida material, serviu como elemento motivador para que aquela população aceitasse se deslocar para trabalhar na Companhia. Este deslocamento significou abrir mão de seu modo de vida e de sua relação com a natureza em bases não monetárias.

E, sobretudo, significou uma reestruturação da vida social. A (re)socialização dessa população na cidade deu-se através do treinamento, da disciplina, do controle e da produção, por meio de sua submissão às novas formas de trabalho então instituídas: assalariamento, horários estabelecidos, tarefas pré-determinadas e produtividade aferida e controlada diariamente, sob a forma de um contrato que regulamentava o conteúdo dos atos sociais. Estava em curso a construção do novo tipo humano exigido pela racionalidade econômica, uma vez que adequado às novas formas de trabalho e produção. Este perfil foi estabelecido em Belterra através da combinação dos mecanismos de coação e consentimento, conforme analisou Gramsci (1988) em seu estudo sobre o fordismo.

Além de toda a infraestrutura construída para fazer funcionar o seu sistema de produção, a CFIB criou uma hierarquia funcional de gerentes, capatazes, trabalhadores mais especializados e peões. Essa hierarquização foi representada (e vivenciada pela população de Belterra) na distribuição das moradias e dos indivíduos no espaço. À individualização do aprendizado, ao controle e à vigilância 
no espaço de trabalho, somou-se a definição funcional dos lugares no espaço de moradia segundo sua utilidade, como veremos adiante, expressando a rede de relações construídas no período, conforme as análises de Foucault (1977) sobre o disciplinamento.

$\mathrm{Na}$ Vila Americana viviam os americanos que coordenavam o projeto. Estes dispunham de espaços de uso exclusivo, como a praça principal para a prática do golfe, jogado aos domingos e o Club House, onde aconteciam as festas para ouvir música e beber uísque. Para os padrões mais exigentes da vestimenta, tinham um alfaiate, de origem sul-africana, que fazia paletós, calças e outros acessórios necessários, além de disporem da padaria e da sapataria do português e da barbearia do barbadiano.

$\mathrm{Na}$ Vila Mensalista, moravam os trabalhadores envolvidos nos cargos de chefia, principalmente em atividades da administração e alguns outros que trabalhavam no hospital, como o farmacêutico, e os russos que faziam o trabalho de autópsia. Lá moravam os trabalhadores mais especializados.

$\mathrm{Na}$ Vila Operária, moravam os trabalhadores com alguma especialização, como mecânicos, marceneiros, carpinteiros e tratoristas. Na Vila Viveiros I e II, moravam aqueles que cuidavam das mudas de seringueiras.

$\mathrm{Na}$ Vila 129 viviam os trabalhadores que desenvolviam as atividades braçais no projeto. Do ponto de vista material, esta vila era próxima ao padrão das casas da Vila Operária, mas tinham como parede folhas de zinco e ficavam mais distantes do centro da cidade, cerca de quatro quilômetros.

Nas proximidades da Vila Mensalista, localizava-se o alojamento onde moravam os rapazes solteiros, que dormiam em redes. Estes não pagavam aluguel pela hospedagem e tinham o serviço de limpeza do local mantido por um zelador da empresa ${ }^{8}$.

A categoria mais baixa na hierarquia sociofuncional da empresa, os campeiros e seringueiros, não moravam em casas com o padrão de vila. Conforme relato de um ex-campeiro que ainda hoje vive em Belterra, eles foram se alocando ao longo das estradas, em casas de palha, com piso de chão, sem água, luz ou telefone. Eram trabalhadores que desenvolviam atividades braçais no campo, como derrubar mata, abrir estradas, cavar buracos com a ajuda de terçado e enxada e plantar mudas das seringueiras.

O controle desses trabalhadores era realizado pelo apontador, que controlava a presença no serviço por meio da anotação da numeração contida em

\footnotetext{
Existiam ainda mais dois espaços sociofuncionais: a Vila Timbó, destinada aos enfermeiros funcionários do Hospital Henry Ford, e a Vila Pequiá, onde moravam os poucos seringueiros e operários que não viviam em cabanas.
} 
uma placa de metal recebida no momento da contratação, e que ficava pendurada no peito do funcionário durante toda a jornada de trabalho. Duas guaritas de segurança funcionavam 24 horas por dia, com telefone para controlar a entrada e saída de pessoas e automóveis, que eram revistados ao entrarem nas propriedades da Companhia. A CFIB exigia, com rigor, uma boa conduta de seus funcionários. Bebida alcoólica era proibida e qualquer deslize era objeto de demissão, segundo "a lei severa dos americanos" (Erasmo, outubro de 2009).

Para fins analíticos, podemos apresentar os elementos estruturantes dessa experiência em Belterra: 1) um conjunto de procedimentos, usos e apropriação do território alheio à gente do lugar, sob a racionalidade do lucro e do uso da técnica mais sofisticada que, na prática, representou um processo de expropriação da natureza das famílias que lá moravam antes da chegada da empresa de Henry Ford; 2) a destruição ou o desarranjo dos modos de vida preexistentes no lugar, com o recrutamento de sua população na área rural e seu deslocamento para a cidade recém-criada para atender às necessidades de mão de obra da Companhia, sendo que o seu ajustamento ao novo modo de vida urbano se deu por meio de um processo de (re)socialização na cidade, que visava constituir o novo tipo humano, disciplinado e hierarquizado, necessário à atividade industrial; 3) o uso predatório da natureza, causado principalmente pelo grande desmatamento e pelas queimadas; 4) a enunciação dos estereótipos e a sociabilidade de evitação por parte dos americanos, pré-figuradas e estimuladas pelo desenho hierarquizado das moradias na cidade, que expressavam a premissa de industrializar a selva, levando até ela a civilização do homem branco; 5) um tipo de urbanização que ainda não havia sido experimentado na região e que contrastou com a pobreza e precariedade dos serviços existentes, no período, nas cidades da Amazônia. Assim, Belterra constitui-se como um enclave, em que o uso dos bens e serviços disponíveis era restrito aos funcionários da Companhia e não extensivo à população residente no entorno ou em outras cidades. Dessa forma, configurou-se como um novo arranjo socioespacial, marcado pela autossuficiência de sua organização e pela mobilidade regulada de pessoas e mercadorias, semelhante ao que analisaram Trindade Jr. e Rocha (2002) sobre as cidades-empresas implantadas na região pelos grandes projetos, a partir de 1970.

Já no período atual, a presença da soja na cidade de Belterra e em seu entorno, realizou-se com base na expropriação da terra dos pequenos agricultores e de moradores da cidade que desenvolviam atividade agrícola, através da compra, fosse esta efetuada por meio da sedução ou da pressão para a venda. Há relatos de ameaças de morte, queimas de casas e enfrentamento público na cidade de Santarém, que expressam as concepções de desenvolvimento e os campos de poder que se formam em torno dessa questão. 


\section{TEMPOS RECENTES: CHEGADA DA SOJA E DO ESTRANHO NA "FALA DO DESENVOLVIMENTO"}

Data do final da década de 1990, a chegada da soja no Oeste do Pará, na área de influência da Rodovia BR-163, mais especificamente nos municípios de Belterra e Santarém que, em poucos anos, transformaram-se nos maiores produtores de soja do estado. O deslocamento do plantio da soja para esta região do país foi programado, resultando de um conjunto de estratégias organizadas pela articulação entre o Estado e o grande capital. Uma ação planejada e seletiva que teve apoio político em diversos níveis, financiamento público em vários casos, flexibilização da legislação ambiental, afrouxamento da fiscalização dos órgãos responsáveis e estudos científicos que subsidiaram a melhor localização do empreendimento?.

O contexto favorável para isso deveu-se ao esgotamento das terras agricultáveis no estado de Mato Grosso, provocado pelo plantio da soja em larga escala e pela abundância de terras disponíveis às margens da Rodovia BR-163, no Pará. Terras devolutas ou terras onde se localizavam os agricultores, advindos com os projetos de colonização do INCRA na década de 1970; os nativos de Santarém e Belterra, e outros provenientes dos municípios integrantes da região do Baixo Amazonas. O preço baixo da terra tornou-a acessível aos produtores capitalizados de fora da região. Acrescente-se a isso os incentivos financeiros e políticos dos governos municipal, estadual e federal para oportunizar novos empreendimentos econômicos na região.

Estudos realizados por meio da cooperação técnica entre os governos federal, estadual e a prefeitura de Santarém produziram informações estratégicas sobre o potencial madeireiro, as terras agricultáveis, a navegabilidade dos rios daquela região e a riqueza do subsolo, que orientaram tanto a ação do governo como do grande capital. O Programa de Integração Mineral em Municípios da Amazônia - PRIMAZ ${ }^{10}$, nos anos de 1990 e, mais recentemente, as proposições acerca do Zoneamento Econômico-Ecológico do Oeste do Pará (ZEE) que, segundo Acselrad (2000, p. 9, 11), "tende a ser a expressão espacializada de algum modelo de desenvolvimento", que pensa o território apenas como base material e

9 O primeiro contato de um dos autores deste artigo, José Carlos Matos Pereira, com essa região e com a chegada da soja a ela foi em fevereiro de 2003, quando realizou sua pesquisa de mestrado sobre o papel das cidades médias na rede urbana regional. Ver a respeito Pereira (2005).

10 O Programa de Integração Mineral em Municípios da Amazônia - PRIMAZ - foi um estudo realizado pela parceria entre Prefeitura Municipal de Santarém e os Governos Estadual e Federal que teve como resultado a identificação do potencial dos recursos minerais, hídricos, florestais, pedológicos e ambientais (CPRM, 1996). 
os "atores regionais" como "empreendedores das vocações ditadas pelo mercado mundial". São ações na região que confirmam essa proposição ${ }^{11}$.

Temos, assim, sob a ótica da velha lógica da integração regional, uma ação articulada entre Estado, produtores de soja, políticos e empresários de Santarém, um campo fértil para deslanchar o empreendimento. Mas este não é um fato novo na região, relacionando-se com a inserção da Amazônia no contexto mais amplo da economia capitalista mundial e ao papel do Estado nacional na região, no que tange ao controle estratégico dos recursos naturais ${ }^{12}$.

Os migrantes chegados à Belterra e Santarém, no final dos anos 90, eram famílias de médios e pequenos produtores de soja, oriundas dos estados de Mato Grosso, Paraná, Rio Grande do Sul e Santa Catarina. Foram recebidos por empresários, proprietários dos meios de comunicação, parte da elite política local e governo municipal como portadores do "progresso" e do "desenvolvimento". Formulações bem próximas à representação do estrangeiro proposta por Simmel (1983), como aquele que traz a novidade, permanece no lugar e é reconhecido por ser de fora, embora não esteja preocupado com a inserção no grupo.

Cerca de 450 famílias de produtores capitalizados já realizaram recentemente deslocamentos migratórios para a Amazônia por conta desta atividade produtiva. As duas entrevistas realizadas com representantes desse segmento indicam seus principais percursos: Rio Grande do Sul/Mato Grosso/Pará; Paraná/Mato Grosso/Pará. Relatos de lideranças sindicais da região informam que poucos

11 Como exemplo, podemos apresentar a entrevista concedida por um ex-prefeito de Santarém a um jornal local sobre a questão da soja. "O prefeito assegura que o Estudo de Zoneamento Agroecológico serviu de instrumento para a orientação dos investimentos nessa área, com um mapeamento das áreas alteradas, através de satélite, apontando onde se poderia aproveitar para o plantio de grãos, sem que houvesse desmatamentos. O salto dado no setor agrícola despertou interesse de empresa de fora, o que fez com que, nos últimos três anos, mais de trinta empresas se instalassem em Santarém. Uma delas foi a Cargill. 'Todos lembram que, em 1997, Santarém não tinha nenhum saco de arroz de forma mecanizada. Por força de um trabalho persistente que nós tivemos, sobretudo de estudos iniciais, depois de divulgação desse potencial de Santarém, nós conseguimos atrair pra cá uma série de empresas, dentre as quais a Cargill que, somando, só tem promovido esse desenvolvimento". Matéria publicada em 31/12/2003. Disponível em: < http://notapajos.globo.com/lernoticias.asp?id=5331>. Acesso em: 24 abr. 2011.

12 Castro (2007, p. 4) também analisa o avanço das práticas predatórias sobre as áreas de florestas em vários estados da região amazônica, ressaltando que as técnicas intensivas usadas, tanto competem com os modelos tradicionais no uso dos recursos naturais, quanto comprometem a biodiversidade e a reprodução social desses grupos. Essas atividades, por exemplo, estão associadas à produção mineral, agrícola, madeireira e à pecuária, cuja ação é geradora de intensos conflitos envolvendo uma diversidade de atores que buscam o controle e o uso do território, seja para a satisfação das necessidades das famílias ou para compor um estoque estratégico de terras para o capital tendo por fim o atendimento das intensas demandas do mercado internacional. Diz a autora, que na rodovia Santarém-Cuiabá (BR-163), no estado do Pará, as situações encontradas são de diversas ordens, como "problemas fundiários, índices elevados de grilagem de terra, violência, atividades econômicas ilegais, concentração da terra e conflitos socioambientais com populações tradicionais". 
vivem na cidade de Santarém, uma vez que se fixaram em áreas mais distantes desta, como as localidades de São José, Boa Esperança, Tabocal, e no município vizinho de Mojuí dos Campos, recém-emancipado de Santarém, onde desenvolvem também outras atividades econômicas no ramo de supermercado, churrascaria, açougue e motéis, por exemplo.

O conflito entre os produtores de soja (os recém-chegados vindos "de fora") e a população local (os antigos moradores do lugar) logo se desenvolveu, envolvendo ameaças, alianças e enunciação de preconceitos. Mas, no contexto da "fala do desenvolvimento", os outsiders da Amazônia, se quisermos fazer uma analogia invertida com a proposição de Elias e Scotson (2000) ${ }^{13}$, são indígenas, mestiços, agricultores, extrativistas, mulheres e trabalhadores urbanos que recebem dos estranhos vindos "de fora" adjetivos pejorativos de "preguiçosos", "pinguços" e são vistos como aqueles que representam entraves para o progresso econômico ${ }^{14}$.

\subsection{O que pensam os "de fora" sobre os "de dentro"}

Nesta seção, examinamos duas entrevistas com produtores de soja que têm propriedades em Belterra - um paranaense e um gaúcho, a fim de analisar os sentidos que os mesmos produzem sobre a vida social do lugar.

Em ambos os casos, a prática agrícola é definida como "primitividade", "uma agricultura fracassada", que "não sabe nem pra que rumo ir", uma vez que não tem dinheiro, sementes, fertilizantes e maquinária. Sem assistência técnica por parte do governo, ainda os agricultores "de dentro" são vistos como aqueles que ainda usam o queimar, brocar e plantar, prática utilizada no sul do país nos anos de 1960, como enfatiza o primeiro entrevistado.

Claro que tem que ter essa tecnologia. Hoje você vai lá no Sul, na Região Sul, você chega num sítio, você vê lá às vezes um mini produtor, um pequeno produtor que tem apenas dois, três hectares. Mas ele tem carro zero na garagem, ele tem uma galinha, se você quiser comer uma galinha na hora, ele tem porco, leite, queijo, linguiça, salame, derivados, tem tudo [...].

13 Esses autores utilizam dois conceitos que denominam de conceitos guarda-chuva: established (estabelecidos), que são aqueles autodenominados de "minoria dos melhores", "guardiães do bom gosto", que ocupam posições de privilégio e poder assentadas na tradição, autoridade e influência; já os outsiders, "os que estão fora da sociedade", constituem um conjunto heterogêneo de pessoas estigmatizadas pelos primeiros como relacionados à delinquência, à violência e à desintegração. Como dizem Elias e Scotson, trata-se de relações pautadas na intolerância, na estigmatização e no poder econômico, político e social.

14 Ver, por exemplo, matéria do jornal Gazeta de Santarém, intitulada "Sojeiros têm preconceito com santarenos" e publicada no Caderno Cidade, p. 3, datado de 23 a 24 de maio de 2006. 
[...] existem melhoramentos assim, mas não tem, por exemplo, uma empresa de pesquisa que seja só pra desenvolver espécies que melhora a vida de produção rural, que é produzir em menos tempo com grande quantidade e qualidade. É o que acontece é isso: hoje a agricultura mecanizada ela dispõe aqui de cultura, as sementes que venham pra cá pra gente de fora. A gente compra de Goiás, compra do Maranhão, do Mato Grosso (Produtor de soja I, março, 2011).

O segundo entrevistado reconhece que a base da atividade agrícola local é feita por pequenos produtores, mas critica o uso do trabalho manual, que define como "arcaico", por torná-los dependentes dos programas sociais do governo. Também reclama que, em Belterra, falta mão de obra capacitada e disponível para o trabalho braçal. Esta é buscada na área rural e urbana de Santarém e no recémcriado município de Mojuí dos Campos. Essa “acomodação” da população local, os "de dentro", seria motivada pela aposentadoria ganha pelos antigos funcionários da CFIB. Mais que isso, sugere, no Norte as pessoas seriam menos afeitas ao trabalho por conta da "generosidade da natureza".

A natureza sempre foi muito generosa no Norte. Eu acho que por isso que às vezes erroneamente algumas pessoas falam que o caboclo trabalha tanto. Mas eu vou dizer assim, numa região que a natureza é tão generosa, você naturalmente, você não precisa se esforçar tanto, vamos dizer assim. Então disso, vem uma questão talvez se pegar do tempo indígena, talvez até milenar.

[...] Então é o seguinte: o que falta é uma especialização das pessoas. Também tem, você deve ouvir isso, como é que algumas pessoas falam, vocação: ah, a região não tem vocação. Eu vou ser até duro: se você olhar pelo que acontece em Santarém e em Belterra, que vocação natural tem, se você não tem nada e as pessoas não sabem nada? Talvez pra prostituição seria vocação. Então o turismo sexual que existe aí. E que todo mundo faz olho grosso, mas que os gringos vêm aqui pra pegar as menininhas de menor aí, que existe isso. Então será que a vocação é essa? Não, eu acho que se você tiver uma indústria e tiver treinamento, essas pessoas vão ter a vocação pra isso. Porque tem que ter um fomento pra geração de emprego. Porque não tem como o governo alcançar através dos programas sociais a vida inteira assim. Então a gente tem uma preocupação pessoal grande em relação a isso (Produtor de soja II, março, 2011).

A sociabilidade dos "de fora" estrutura-se a partir da evitação da convivência com "os de dentro", apartada da vida da cidade, embora o discurso dos entrevistados contenha um certo um teor de cordialidade, ao afirmar que em Belterra "as pessoas são acolhedoras", "são pessoas simples", com as quais guardam relações de "amizade". Mas o círculo social de pertencimento e convívio é desenvolvido com os próprios pares, em atividades coletivas que acontecem na localidade de São José, como churrascos, festas e encontros semanais, ou em atividades promovidas pelo Sindicato Rural de Santarém para os seus associados ${ }^{15}$.

15 Vale ressaltar que identificamos, por meio da fala dos entrevistados e em situações verificadas em campo, poucos casos de envolvimento desse segmento com a vida social da cidade, entre 
Na percepção de nosso segundo entrevistado, produtor de soja, os pequenos agricultores não têm a capacidade de administrar o dinheiro público recebido, nem "vocação" e interesse de trabalhar na terra. Daí o fracasso das iniciativas do governo em relação a esse segmento. Assim, conclui - a terra "mal usada" deve estar livre para que a soja possa ocupar grandes extensões de terra, produzir em grande escala para o mercado internacional e gerar riquezas e novos postos de trabalho na região.

Esse discurso não considera o que a agricultura mecanizada desestrutura, visto que, segundo suas premissas, o lugar é destituído de vida organizada. A outra questão a ser observada é que o olhar desse segmento de produtores de soja se volta para as terras que ainda estão protegidas por algum tipo de legislação ou para aquelas que ainda não foram incorporadas ao mercado de terra da soja, conforme podemos aferir pelos discursos abaixo.

São 2 milhões e 700 mil hectares nos municípios [Santarém e Belterra]. Considerando que esses dois municípios têm levantado pelo zoneamento econômico ecológico, o último zoneamento que foi feito, o segundo, aliás, detectado nos dois, nós temos mais ou menos uns 500 mil hectares de área antropizada. Destes 500 mil utilizados mesmo, nós temos, pra agricultura aí se der uns 70 mil, entre soja, milho, arroz... Então nós usamos muito pouco do nosso espaço aqui ainda e sem necessitar, por exemplo, adentrar as áreas de floresta virgem e esse tipo de coisa. Hoje a atividade de soja usa, juntando os dois municípios, em torno de 1,2\% da área (Produtor de soja I, março, 2011).

Hoje já foi feito um levantamento, Santarém e Belterra têm 3 milhões e 100 mil hectares [...] se a lei permite $20 \%$ isso daria direito de 1 milhão de hectares, já daria direito de 200 mil hectares. De 3 milhões já daria direito 600 mil hectares. Estão sendo cultivados hoje 20 mil hectares. A produção de soja hoje está sendo em torno de 1 milhão de sacas. 1 milhão de sacas são 20 mil hectares. 20 mil hectares lá no Mato Grosso às vezes é um produtor só (Produtor de soja II, março, 2011).

Para situações dessa magnitude, as mensagens das campanhas educativas que postulam a conversão individual por meio da tomada da "consciência ecológica" pouco ajudariam, conforme propõe Acselrad (2004) ao analisar os conflitos socioambientais. O "homem" predador, nesse contexto, pertence a uma classe social abastada, dispõe de capital para bancar o empreendimento, de apoio político e institucional, de tecnologia de ponta e da certeza da impunidade diante das fragilidades governamentais em relação à fiscalização e ao fazer cumprir a lei, embora em seu discurso afirme seguir a lei e se revele injustiçado e perseguido pelos órgãos estatais ligados ao meio ambiente.

eles um casamento de um produtor de soja com uma jovem da cidade de Belterra, mas este fato constitui-se em exceção. 


\subsection{O que pensam os "de dentro" sobre os "de fora"}

E o que pensam os "de dentro" sobre a presença da soja na cidade e no seu entorno e a atuação dos produtores de soja no lugar? Nesta seção, analisamos várias entrevistas dos moradores do lugar, com o objetivo de identificar suas percepções sobre esses temas em suas narrativas ${ }^{16}$.

A população local apresenta os produtores de soja como os responsáveis pelo desmatamento na cidade e pela mudança do clima. "Gaúchos" e "sojeiros" são os termos de nominação destes. Embora existam produtores de soja paranaenses, matogrossenses, catarinenses, "gaúcho" é o termo de classificação operado pelos moradores da cidade para os "de fora" que produzem soja.

Pessoas que moram nas proximidades das plantações relatam doenças respiratórias em adultos e crianças, mau cheiro e moscas que invadem as residências. Também identificam os mecanismos de sedução de famílias para a venda da terra, como oferta de dinheiro, carros e motos.

“Tá mais quente devido à desmatação. Não há mais aquele friozinho, por isso, sempre procuramos os rios e igarapés".

"Está muito quente por conta da devastação provocada pelos "gaúchos" por causa da plantação de soja. $\mathrm{Na}$ estrada 9, que leva ao Aramanai e Maguari era mata fechada, mas agora não tem mais, até as próprias castanheiras, pequizeiros, as plantas nativas não têm mais".

"Muita gente vendeu, mesmo as pessoas que moravam aqui trocaram seus terrenos por moto, carro velho, pouco dinheiro e foram morar na periferia de Santarém. [...] $\mathrm{Na}$ estrada da revolta teve muita gente que trocou os seus terrenos por besteira, achavam que $\mathrm{R} \$ 5.000,00$ (cinco mil reais) era dinheiro”.

"Há 20,30 anos atrás Belterra tinha outro clima, é a "desmatação" às proximidades da área urbana. Antigamente o clima era de montanha, para tomar um banho no fim de tarde era necessário jogar uma bolinha antes. Quando eu ia buscar minha mãe de bicicleta, que trabalhava no Hospital Henry Ford, tinha aquela névoa".

"Aqui na estrada 1, depois do Hospital, quando chegou os "gaúchos" para lá, toda aquela área era de mata, ele derrubou e começou a plantar milho, arroz e soja e ele começou a usar agrotóxico que deixou um cheiro forte e as casas próximas foram invadidas pelas moscas, muito prejudicial para as pessoas, principalmente, para as crianças".

"A nossa mata aqui já foi praticamente devastada na área urbana. Você vai ver que tem muita mata derrubada. O povo que veio de fora do Mato Grosso, do sul, tem uma cultura diferente da nossa". [...] Se você for na cultura deles, eles vão matando tudo, destruindo tudo".

16 Em sua pesquisa de doutoramento, José Carlos Matos Pereira realizou 44 entrevistas com a população do lugar, de modo a apreender os sentidos que conferem aos dois contextos analisados. Selecionamos para este artigo alguns poucos trechos destas, relativos ao segundo caso estudado, para demonstrar, com base nos dados empíricos, as percepções e representações dos "de dentro" em relação ao contexto vivido com a chegada da soja. 
No plano das representações sobre que tipo de "desenvolvimento" desejam para o lugar, a soja não aparece associada a novas oportunidades. Os conteúdos das falas sempre remetem ao turismo, às indústrias, aos bancos, à ampliação do comércio e dos serviços. Do mesmo modo, os "de dentro" não se reconhecem; não se identificam com os "de fora", cujas práticas denunciam como danosas à saúde e ao meio ambiente. Esses elementos são demarcadores das diferenças, da afirmação da identidade do lugar e dos diferentes valores e moralidades que envolvem as racionalidades e ações dos grupos sociais envolvidos, bem como das temporalidades da vida social, bem demarcadas pelos moradores da cidade como distintas, o antes e o depois da chegada da soja ao lugar.

Para os moradores mais velhos, o plano de referência se associa, muitas vezes, ao passado da CFIB, ao clima suave das manhãs e noites, relacionado ao "orvalho" e ao clima de montanha. Para o tempo presente, duas ideias mostram consistência e regularidade: a tranquilidade e a segurança - não haveria perigo de assalto ou violência, que também estão associadas às belezas naturais do lugar, como as praias e a floresta, e ao jogo de futebol nos fins de semana. No entanto, reclama-se da falta de oportunidades de trabalho e da pouca circulação de dinheiro na cidade.

"Viver em Belterra é um paraíso, não tem violência, não tem preocupação com roubo. Não troco Belterra por outra cidade".

"Aos finais de semana, vamos à praia tomar banho e comer churrasco de carne e peixe com os amigos".

"Só falta entrar e sair mais recursos. Aqui não tem banco. O pessoal recebe e gasta em Santarém devido ter mais comércio e ser mais barato. A gente recebe em Santarém e já faz as compras por lá [...] agora com o micro-ônibus a viagem ficou mais rápida".

"Aqui em Belterra tem condições de receber várias indústrias".

"Aqui o que tem são os aposentados, pensionistas e o pessoal da prefeitura".

"Aqui devia ter uma agência bancária para fazer o dinheiro circular aqui mesmo".

Observamos também que a discussão socioambiental se faz presente em enunciados como: "desmatamento" ou "desmatação", "mudança no clima”, "cultura diferenciada", "desenvolvimento", "seca", "enchente”, "destruição da natureza". São termos que fazem parte do universo vocabular e da representação da mediação do lugar com a totalidade-mundo. Os eventos políticos dentro e fora da região, a presença de ONGs no município, as viagens de jovens de Belterra para outros países por meio de intercâmbio cultural, o ponto de inclusão digital, os conflitos envolvendo produtores de soja e movimentos em Santarém e Belterra - com maior intensidade no ano de 2006 -, a elaboração da Lei do Plano 
Diretor Participativo do município, as informações que circulam nas escolas, na TV, no rádio e aquelas envolvendo as ações em torno do asfaltamento da BR163 , tudo isto faz com que esse debate ganhe visibilidade local, regional, nacional e internacional. Inclusive o príncipe Charles, herdeiro do trono inglês, esteve na Floresta Nacional do Tapajós (FLONA) em sua viagem ao Brasil, no ano de 2009.

Temos, então, sob a racionalidade dos modos de vida do lugar, o uso e apropriação da natureza e do espaço em bases mais equitativas e de forma socioambiental mais "sustentável". Sua preocupação principal reside em usar a natureza para satisfazer as necessidades familiares imediatas e duradouras, mas também se relaciona a uma visão de longo prazo com base na disponibilidade permanente desses recursos. Daí, a ideia de não desmatar, de não caçar além do que se precisa, de não plantar para além do que se pode usar. Embora não neguem a necessidade de comercializar quando há excedente e, muitas vezes, proponham a implantação de indústrias para aproveitar as toneladas de frutas que estragam nos quintais das casas, já que não existe mercado para tanta produção.

\section{CONSIDERAÇÕES FINAIS}

Como últimas considerações, podemos argumentar que o fio condutor entre os dois períodos - da experiência do Plantation de seringa de Henry Ford (1934-1945) e da presença da soja na cidade nos anos 2000 - remete a diferentes racionalidades que motivam a ação dos grupos sociais e econômicos, destacando que ação do capital com base no apoio estatal destruiu ou desarranjou o modo de vida do lugar, e foi demandante de grandes porções de terra. Isso implicou o uso intensivo e predatório da natureza e a expropriação da terra da população local.

Em ambos os casos, o "outro" (os "de dentro") foi desumanizado e colocado em posição de inferioridade, para justificar uma modernização capitalista pelo alto, em que a destruição dos modos de vida do lugar constituiu-se como a condição de possibilidade para que o valor de troca se sobrepusesse ao valor de uso. Belterra foi reinventada, articulando-se rural e urbano, segundo as modalidades específicas de inserção da Amazônia na divisão internacional do trabalho, a partir da "fala do desenvolvimento". Assim, em cada um dos contextos examinados, esta serviu de argumento legitimador para a instauração de novas técnicas com base na mecanização, desqualificando o uso primeiro da população do lugar, nominado como "arcaico" e "primitivo", por conta da técnica simples do machado, da enxada, do terçado e do uso da natureza, prioritariamente, para a satisfação das necessidades humanas em bases não mercantis. 
Diferentemente do período da CFIB, o que ocorre no período atual é que há resistência política de um campo de poder representado por organizações sociais de toda região do Baixo Amazonas, que se opõem à presença da soja e propõem outra perspectiva de desenvolvimento. A dimensão multiescalar da ação desse campo chegou até a negociar com os compradores de soja na Europa e conquistar a "moratória da soja”, que impôs restrições à prática predatória e proibiu a compra desse produto, caso esta se realizasse com base no desmatamento e na expropriação da terra dos pequenos agricultores.

Podemos, por fim, identificar como ameaças para os modos de vida do lugar as seguintes situações: a mobilização do capital em torno da flexibilização da legislação ambiental existente, e pela não regularização da posse da terra dos pequenos agricultores, visto que esta, em um curto prazo, pode ser incorporada ao mercado de terra da soja; a fragilidade fiscalizadora e repressiva do Estado para coibir práticas predatórias; os incentivos fiscais e financeiros oriundos do governo federal para atividades de produção da soja, por conta da balança comercial brasileira. Esses movimentos, conforme Almeida (2009), constituíramse nas "estratégias do agronegócio". Esse processo inclui, ainda, a fragilização da base social dos agricultores familiares nos enfrentamentos seguintes por conta da estratégia de cooptação desenvolvida pelo sindicato patronal ligado à soja, de sua base política e das ameaças de morte que vêm sofrendo várias de suas lideranças.

\section{REFERÊNCIAS}

ACSELRAD, H. As práticas espaciais e o campo dos conflitos ambientais. In: Conflitos ambientais no Brasil. Rio de Janeiro: Relume Dumará, 2004. p. 13-35.

O zoneamento ecológico-econômico e a multiplicidade de ordens socioambientais na Amazônia. Novos Cadernos NAEA, Belém, v. 3, n. 2, p. 5-15, dez. 2000.

ALMEIDA, A. W. B. de. Agroestratégias e desterritorialização: os direitos territoriais e étnicos na mira dos estrategistas dos agronegócios. In: ALMEIDA, A. W. B. de; CARVALHO, G. (Orgs.). O Plano IIRSA visão da sociedade PanAmazônica. Belém: FASE; Observatório COMOVA/UFPA, 2009. p. 57-105.

AMORIM, A. T. dos S. A dominação norte-americana no Tapajós. Santarém: Tiagão, 1995.

CALDEIRA, T. P. do R. Cidade de Muros. São Paulo: EDUSP, 2000. 
CÂNDIDO, A. Parceiros do Rio Bonito. São Paulo: Duas Cidades, 1971.

CASTRO, E. Políticas de ordenamento territorial, desmatamento e dinâmicas de fronteira. Novos Cadernos NAEA, Belém, v. 10, n. 2, p. 105-126, dez. 2007.

COSTA, F. de A. Grande Capital e Agricultura na Amazônia: a experiência Ford no Tapajós. Belém: EDUFPA, 1993.

CPRM - COMPANHIA DE PESQUISA DE RECURSOS MINERAIS. Superintendência Regional de Belém. Inventário florestal de avaliação preliminar do potencial madeireiro do município de Santarém. Belém, 1996. (CD-ROM).

CRULS, G. Impressões de uma visita à Companhia Ford Industrial do Brasil. Revista Brasileira de Geografia, v. 1. n. 4, p. 3-22, out. 1939.

ELIAS, N. O processo civilizador. Rio de janeiro: Zahar, 1994. v. 1.

ELIAS, N.; SCOTSON, J. L. Os Estabelecidos e os Outsiders: sociologia das relações de poder a partir de uma pequena comunidade. Rio de Janeiro: Zahar, 2000. FOUCAULT, M. Disciplina. In: Vigiar e punir. Petrópolis: Vozes, 1977. p. $125-152$.

GOFFMAN, E. Estigma: notas sobre a manipulação da identidade deteriorada. Rio de Janeiro: Zahar, 1982.

GRAMSCI, A. Maquiavel, a política e o Estado moderno. Rio de Janeiro: Civilização Brasileira, 1988.

GRANDIN, G. Fordlândia: ascensão e queda da cidade esquecida de Henry Ford na selva. Rio de Janeiro: Rocco, 2010.

LEFEBVRE, H. O direito à cidade. São Paulo: Moraes, 1991.

PEREIRA, J. C. M. Importância e significado das cidades médias na Amazônia: uma abordagem a partir de Santarém (PA). 2005. Dissertação (Mestrado em Desenvolvimento Sustentável do Trópico Úmido) -

Núcleo de Altos Estudos Amazônicos, Universidade Federal do Pará, Belém, 2005. MENDES, A. A Invenção da Amazônia. Belém: UFPA, 1974.

MENDONÇA, S. R. de. Estado e sociedade: a consolidação da república oligárquica. In: LINHARES, M. (Org.). História geral do Brasil. Rio de Janeiro: Campus, 1990. 
PIQUET, R. Cidade-empresa: presença na paisagem urbana brasileira. Rio Janeiro: Zahar, 1998.

SANTOS, M. A natureza do espaço. São Paulo: EDUSP, 2006.

SENA, C. Fordlândia: breve relato sobre a presença americana na Amazônia. Cadernos de História da Ciência, v. 4. n. 2, jul./dez., p. 90-107, 2008.

SIMMEL, G. O estrangeiro [1908]. In: MORAIS FILHO, E. de (Org.). Georg Simmel: Sociologia. São Paulo: Ática, 1983.

TRINDADE JR, S.-C.; ROCHA, G. M. Cidade e empresa na Amazônia: uma apresentação do tema. In: TRINDADE JR, S.-C.; ROCHA, G. M. (Orgs.). Cidade e empresa na Amazônia: gestão do território e desenvolvimento local. Belém: Paka-Tatu, 2002. p. 13-23.

VIANNA, L. W. Liberalismo e sindicato no Brasil. Rio de Janeiro: Paz e Terra, 1978.

\section{OUTRAS FONTES:}

Entrevistas realizadas nos meses de outubro e novembro de 2009 e em março de 2011

- Tica, 72 anos, ex-cozinheiro do Hospital Henry Ford.

- Erasmo, 78 anos, ex-seringueiro.

- Produtor de soja I, gaúcho, 42 anos.

- Produtor de soja II, paranaense, 30 anos.

- Liderança sindical de Santarém, 36 anos, agricultora, ameaça de morte.

- Moradora da cidade de Belterra, 38 anos, funcionária pública.

- Morador da cidade de Belterra, vizinho da plantação de soja, 54 anos.

- Morador da área rural de Belterra, 64 anos, agricultor deslocado com a soja.

\section{Jornais}

- Jornal Folha do Norte de 01/01/1934.

- Jornal Folha do Norte de 05/10/1940.

- Jornal Folha de São Paulo de 10/10/1970.

- Jornal A Gazeta de Santarém de 23/05/2006. 
